\title{
CRIANÇA E APROPRIAÇÃO TECNOLÓGICA: UM ESTUDO DE CASO MEDIADO PELO USO DO COMPUTADOR E DO TABLET
}

\author{
D. J. FRANCISCO* e A. P. L. SILVA \\ Universidade Federal de Alagoas \\ deisej@gmail.com*
}

Artigo submetido em janeiro/2015 e aceito em novembro/2015

DOI: $10.15628 /$ holos.2015.2702

\section{RESUMO}

Estamos constantemente fazendo uso dos mais diferenciados recursos tecnológicos, como por exemplo, computador, tablet, celular, internet, entre outros, nas mais simples atividades do nosso cotidiano. O foco principal deste trabalho consiste em abordar o processo de interação de uma menina de seis anos de idade com computador e tablet. Por meio deste trabalho, é relatado como tal criança interagiu com estes recursos tecnológicos durante quatro sessões de observação, a partir da perspectiva vygotskiana, em especial no conceito de cultura. Este trabalho foi elaborado por meio da abordagem qualitativa, utilizando como delineamento o estudo de caso. Para a coleta de dados foram utilizadas observações e em alguns momentos diálogos orientados por roteiro e em outros não, com a criança. Os resultados encontrados apontam que mesmo sem fazer uso de computador e do tablet a criança já tinha um conhecimento prévio sobre estes equipamentos e, ao longo da pesquisa, foi se apropriando cada vez mais de informações sobre a usabilidade destes recursos, mesmo estando em processo inicial de aquisição do código escrito.

PALAVRAS-CHAVE: Tecnologia, Interação, Criança.

\section{CHILD AND TECHNOLOGICAL APPROPRIATION: A CASE STUDY MEDIATED BY THE COMPUTER AND THE TABLET USAGE}

\begin{abstract}
We are constantly making use ofa variety of technological resources, e.g.: computer, tablet, cellular phone, internet; among others, in the simplest activities of our daily life. The main focus of this study is to address the six-year-old girl's interaction, who has not frequent contact with computer and tablet. By means of this paper, it is reported as such child interacted with these technological resources for four observation sessions, from the vygotskian perspective.This paper was prepared through the qualitative approach, using it as a
\end{abstract}

design, the case study. For data collection were used observations and at some times, dialogue driven by screenplay and in others no, with the child. The results show that even without having to use computer and tablet, the child had prior knowledge about these devices and, throughout the research, the child was increasingly appropriating information about the usability of these resources, even being under the initial process of acquisition of the written code.

KEYWORDS: Technology, Interaction, Child. 


\section{INTRODUÇÃO}

As tecnologias estão muito presentes em nossas tarefas diárias, por esta razão é quase impossível se esquivar delas. O mundo está cercado de tecnologias de vários tipos, tamanhos e utilidades. Foi o fato de estarmos inseridos em uma sociedade que vive cercada de tecnologias que escolhemos adentrar em uma realidade presente na vida de muitas crianças brasileiras a fim de compreender como se dá a interação delas com os recursos tecnológicos, mais especificamente, o computador e o tablet.

Desse modo, a temática nos interessa pelo fato de estarmos inseridos em uma sociedade na qual os recursos tecnológicos se tornaram importantes elementos constitutivos de nossas vidas e também na de muitas crianças. O computador e o tablet são equipamentos eletrônicos que gradativamente vem fazendo parte da rotina de muitas crianças brasileiras, principalmente, das que fazem parte da classe média e alta. Esses equipamentos, cada vez mais comuns, estão presentes em vários ambientes que a criança acaba frequentando, a exemplo da escola, a casa de amigos, o trabalho dos pais e, às vezes, a própria residência.

Cada tecnologia, por sua vez, tem a sua especificidade e precisa ser compreendida como um componente cultural. Neste sentido, Kenski afirma que (2007, p. 21) "o homem transita culturalmente mediado pelas tecnologias que Ihe são contemporâneas. Elas transformam sua maneira de pensar, sentir, agir".

A criança interage com o computador por meio da exploração do equipamento, sendo que cada criança apresentará motivação e uso diferenciados na utilização desse recurso. Por ser então muito presente, o computador torna-se um forte atrativo para esses sujeitos que acabam utilizando-o como um brinquedo, quando interagem sobre ele como um jogo prazeroso. Desse modo, os chamados ambientes de expressões orais, gráficas e lúdicas no computador permitem que a criança faça uso do jogo simbólico1, ou seja, a criança utiliza o computador como um brinquedo carregado de valores culturais, entrando no mundo imaginativo e de faz-de-conta.

Na perspectiva de Freire (1984, p.11), "a leitura do mundo precede a leitura da palavra". Da mesma forma, a aprendizagem se dá desde o início da vida, antes da entrada em instituições formais de ensino-aprendizagem. Um estudo sobre a compreensão de crianças sobre uso de computadores e sobre sua forma de apropriação se justifica em um curso de Formação de Professores que articula diversos saberes com o uso consciente e educativo das tecnologias no campo da educação.

Este estudo é importante pelo fato de as tecnologias estarem cada vez mais presentes no nosso cotidiano, e esses recursos vem modificando a rotina de muitas crianças. Para tanto, é importante discutirmos a inserção dessas ferramentas na rotina dos sujeitos analisados.

Diante do exposto, chegamos à seguinte questão: como uma criança que está em processo de alfabetização e que nunca teve contato direto com o computador e tablet interage com esses recursos tecnológicos? Esta questão central desdobra-se em outros pontos secundários, a saber: como este sujeito fala sobre este recurso? Como se dá a interação da criança com o computador? Como a criança utiliza o recurso tecnológico? Qual o seu entendimento acerca da tecnologia? 
Ao longo deste trabalho, objetivamos analisar como uma criança interage com o computador e tablet. Especificamente, buscaremos: 1) avaliar, por meio da fala da criança, quais são suas concepções sobre tecnologia, em especial o computador e tablet; 2 ) verificar como se deu a escolha de softwares por ela.

\section{METOdOLOGIA}

Para alcançar os objetivos traçados nesta pesquisa utilizamo-nos do estudo qualitativo. Como método escolheu-se o estudo de caso. O primeiro descreve a complexidade de determinado problema e a interação de certas variáveis (DIEHL; TATIM, 2004, p. 52); já o segundo, conforme Yin (2005) baseia-se na investigação empírica de um fenômeno contemporâneo dentro do contexto da vida real, especialmente quando os limites entre o fenômeno e o contexto não são claramente definidos.

Foram feitas quatro observações e perguntas para analisar como se dava a interação de uma criança com o computador e o tablet. As observações aconteceram do dia 26 de agosto até o dia 30 do mesmo mês, no ano de 2013. Através da fala da criança observada buscamos entender quais as suas concepções acerca do que é um computador; no que o computador se difere de outros artefatos tecnológicos (computador x TV; jogo digital x jogo no real).

O sujeito escolhido para participar desta pesquisa foi uma criança com seis anos de idade, que já fizesse o uso articulado da linguagem, podendo justificar o que pensa sobre os artefatos tecnológicos, nesse caso, o computador e o tablet. Buscou-se como fator importante na escolha dessa criança, além da faixa etária, a falta de contato com esses equipamentos eletrônicos.

Houve, inicialmente, uma conversa com os pais da criança sobre a pesquisa, logo, um pedido de autorização para que ela pudesse participar do trabalho. Entregamos aos pais da criança um termo de consentimento livre e esclarecimento (TCLE) e um termo de assentimento (TA). Após o consentimento - via TCLE e do TA - foi iniciada a coleta de dados.

Para atingir os objetivos propostos nesta pesquisa, a saber: como uma criança que não faz uso do computador e do tablet interage com esses recursos, foram escolhidas as seguintes técnicas de coleta de dados: entrevista (diálogo) e observação.

Durante os quatro dias de observações foram realizadas filmagens do momento da interação da criança com o computador e com tablet e em seguida foram transcritas as informações dessa interação. A análise dos dados teve como base a verificação da interação e da fala da criança, conforme os objetivos da pesquisa, buscando identificar como a criança interagia com o computador e com tablet; qual a concepção da criança sobre estes recursos e como a criança utilizava estes recursos.

\section{REFERENCIAL TEÓRICO}

As tecnologias são muito antigas, sendo que sua origem está ligada à capacidade cognitiva do homem. Através desta engenhosidade, o homem criou e continua criando diferentes tecnologias. Vivemos, portanto, em um momento onde não podemos fugir das tecnologias, uma 
vez que surgem cada vez mais inovações tecnológicas que interferem diretamente em nosso dia a dia. Segundo Kenski (2007, p. 15):

As tecnologias são tão antigas quanto à espécie humana. Na verdade, foi a engenhosidade humana, em todos os tempos, que deu origem às mais diferenciadas tecnologias, o uso do raciocínio tem garantido ao homem um processo crescente de inovações. Os conhecimentos daí derivados, quando colocados em prática, dão origem a diferentes equipamentos, instrumentos, recursos, produtos, processo, ferramentas, enfim, a tecnologias.

De acordo com a autora, os sujeitos pensam nas tecnologias apenas como máquinas, equipamentos e aparelhos, mas as tecnologias vão além delas. Seu conceito engloba a totalidade de coisas que a engenhosidade humana conseguiu criar em todas as épocas, suas formas de uso, suas aplicações. A linguagem, por exemplo, é um tipo específico de tecnologia que não se apresenta através de máquinas e equipamentos.

A autora mostra em sua obra Educação e Tecnologias: o novo ritmo da informação que ao conjunto de conhecimentos e princípios científicos que se aplicam ao planejamento, à construção e à utilização de um equipamento em um determinado tipo de atividade, chamamos de "tecnologia". Ela discute ainda que:

O uso do raciocínio tem garantido ao homem um processo crescente de inovações. Os conhecimentos daí derivados, quando colocados em prática, dão origem a diferentes equipamentos, instrumentos, recursos, produtos, processos, ferramentas, enfim, a tecnologias (KENSKI, 2007, p. 15).

As tecnologias são de suma importância porque nos auxilia frequentemente. Os recursos tecnológicos, por conseguinte, vêm alterando o comportamento dos sujeitos, tanto individualmente como o de todo o grupo social. Ou seja, vivemos cercados de tecnologia e as utilizamos cada vez mais em nossas tarefas diárias, o que significa que ao longo do tempo essa experiência tem transformado a nossa maneira de viver; por exemplo, quando fazemos compras online ou nos comunicamos pelo bate-papo. Percebe-se, dessa forma, que os recursos tecnológicos (computador, tablet, internet, celular, entre outros) estão transformando a forma de viver dos sujeitos, isto é, as tecnologias estão interferindo diretamente em suas rotinas se, por isso, "ampliam a nossa memória, garantem novas possibilidades de bem-estar e fragilizam as capacidades naturais do ser humano." (KENSKI, 2007, p. 19).

É importante destacar que as TIC2, em conformidade com Kenski, não são simples suportes tecnológicos, uma vez que "elas têm suas próprias lógicas, suas linguagens e maneiras particulares de comunicar-se com as capacidades perceptivas, emocionais, cognitivas, intuitivas e comunicativas das pessoas." (2007, p. 38). E o homem transita culturalmente mediado pelas tecnologias que lhes são contemporâneas.

Ao longo do tempo, o conceito de infância sofreu transformações. Afinal, nem sempre a criança foi vista como um sujeito que precisava de cuidados especiais para se desenvolver. Antes a criança era vista apenas como um adulto em miniatura, não sendo valorizada. Nesse sentido, convivia com muitos adultos, aprendendo, assim, seus ofícios. Entrava então no mundo adulto de forma precoce. 
O conceito de infância passa a se estabelecer nos séculos XVI e XVIII. Em virtude disso, esse período passa a ser entendido como uma fase delicada e complexa e como uma categoria social e histórica. Segundo o Referencial Curricular Nacional para Educação Infantil "A concepção de criança é uma noção historicamente construída e consequentemente vem mudando ao longo dos tempos, não se apresentando de forma homogênea nem mesmo no interior de uma mesma sociedade e época.". (1998, p. 21).

Dessa maneira, cada sociedade, em seu tempo, formará uma concepção sobre o que é a criança e qual é o seu papel dentro dessa sociedade. De acordo com o DCNEI $(2010$, p. 12) a criança é:

Sujeito histórico e de direitos que, nas interações, relações e práticas cotidianas que vivencia, constrói sua identidade pessoal e coletiva, brinca, imagina, fantasia, deseja, aprende, observa, experimenta, narra, questiona e constrói sentidos sobre a natureza e a sociedade, produzindo cultura.

Dessa forma, as visões sobre a infância vão se estabelecendo social e historicamente, sendo que a criança agora passa a ser vista como um sujeito social e histórico que é caracterizado pelas contradições da sociedade ao qual pertence. Ainda segundo o Referencial Curricular Nacional para Educação Infantil (1998, p. 21):

A criança como todo ser humano, é um sujeito social e histórico e faz parte de uma organização familiar que está inserida em uma sociedade, com uma determinada cultura, em um determinado momento histórico. É profundamente marcada pelo meio social em que se desenvolve, mas também o marca. A criança tem na família, biológica ou não, um ponto de referência fundamental, apesar da multiplicidade de interações sociais que estabelece com outras instituições sociais.

Além de ser um sujeito social e histórico, a criança é também cidadã e pessoa detentora de direitos que produz cultura e interage com o mundo ao seu redor, criando assim sua própria visão de mundo. Segundo o Referencial Curricular Nacional para Educação Infantil (1998, p. 21):

As crianças possuem uma natureza singular, que as caracteriza como seres que sentem e pensam o mundo de um jeito muito próprio. Nas interações que estabelecem desde cedo com as pessoas que lhe são próximas e com o meio que as circunda, as crianças revelam seu esforço para compreender o mundo em que vivem as relações contraditórias que presenciam e, por meio das brincadeiras, explicitam as condições de vida a que estão submetidas e seus anseios e desejos. No processo de construção do conhecimento, as crianças se utilizam das mais diferentes linguagens e exercem a capacidade que possuem de terem ideias e hipóteses originais sobre aquilo que buscam desvendar. Nessa perspectiva as crianças constroem o conhecimento a partir das interações que estabelecem com as outras pessoas e com o meio.

Quando falamos em infância não podemos esquecer que não há apenas uma infância, mas diversas infâncias, afinal, somos sujeitos sociais inseridos em uma sociedade com a mesma cultura, porém, vivemos em ambientes culturais diferenciados. Por essa razão, não existe apenas uma infância, mas infâncias que vão sendo construídas a partir de elementos culturais e históricos diferenciados - raça, etnia, situação econômica, sociocultural, entre outros. 
Ao falarmos de infância, logo vem em mente o desenvolvimento infantil. 0 desenvolvimento faz parte da condição humana e é um processo contínuo e complexo que se estabelece mesmo antes do nascimento. $O$ sujeito se desenvolve por meio da interação de fatores internos (orgânicos) e externos (meio social); sendo o meio social (cultura) um importante elemento que auxilia o desenvolvimento humano. Sobre isso Mota $(2007$, p. 41) afirma que:

O desenvolvimento humano é um processo de eterna aprendizagem. Desde o nascimento o sujeito enfrentará mudanças gradativas, mas contínuas. Neste processo, cada pessoa, à sua maneira, no seu tempo e espaço sócio cultural, dará sentido à sua vida.

Diante disso, escolheu-se como base para esta pesquisa a teoria histórico-cultural de Vygotsky (1998) para se pensar o desenvolvimento da criança. Acredita-se, nessa teoria, que o sujeito se desenvolve por meio da interação que estabelece com o meio ao qual está inserido. A teoria vygotskyana nos ajuda a refletir sobre a criança que está inserida em uma sociedade onde cada vez mais as tecnologias fazem parte de suas vidas. Sendo assim, fica evidente que em meio a uma sociedade que faz o uso constante dos recursos tecnológicos, que as crianças dessa sociedade irão apropriar-se cada vez mais dessa cultura.

Na perspectiva de Vygotsky3, o sujeito se desenvolve por meio da cultura a qual está inserido, por meio da interação com o outro e também por meio da linguagem. Dessa forma, o sujeito é também construtor da cultura. Nesse sentido, o homem é um ser histórico-social e histórico-cultural que vai se moldando pela cultura que ele mesmo cria.

O homem é o único ser que possui capacidade de desenvolver atividade mental, sendo resultado da apropriação cultural e social que o sujeito internaliza ao longo do tempo dentro da sociedade que ele pertence. Pode-se dizer então que o desenvolvimento humano é cultural, mas também histórico. Isso porque o sujeito vai ao longo do tempo se transformando e transformando a natureza em que está inserido; sendo, portanto, o sujeito o seu próprio autor.

A cultura na perspectiva de Vygotsky é um elemento pertencente à vida social do sujeito, ou seja, a cultura nada mais é do que a prática social que se constitui por meio das relações sociais vivenciadas pelos sujeitos. São as relações sociais que caracterizam as mais diferenciadas sociedades. De modo geral, a cultura é o conjunto das produções humanas, ou seja, cultura é tudo aquilo que o homem produz como as técnicas, as produções artísticas e científicas, as tradições, as suas instituições sociais e também as práticas sociais; logo, a cultura é um elemento que se estabelece por meio de instrumentos técnicos e simbólicos da atividade humana. Assim, quanto às funções psicológicas superiores no desenvolvimento da criança há dois momentos:

Primeiro no nível social, e, depois, no nível individual; primeiro entre pessoas (interpsicológica), e, depois, no interior da criança (intrapsicológica). Isso se aplica igualmente para atenção voluntária, para a memória lógica e para a formação de conceitos. Todas as funções superiores originam-se das relações reais entre indivíduos humanos. (VYGOSTSKY, 1998, p.75).

Nesse contexto, a interação com o outro é um elemento importante para a constituição cultural de cada sujeito. $O$ homem se torna um ser cultural a partir do momento em que o mundo adquire significação. Logo, pode-se concluir que para a teoria Vygotskyana a cultura é um elemento 
produzido por meio da vida e atividade social dos sujeitos, sendo tudo aquilo que o homem produz ao longo da sua existência. A cultura é um elemento da vida humana que se constrói a partir da vida e da história do próprio sujeito. Quanto a isso, Vygotsky diz que:

A história do desenvolvimento das funções psicológicas superiores seria impossível sem um estudo de sua pré-história, de suas raízes biológicas, e de seu arranjo orgânico. As raízes do desenvolvimento de duas formas fundamentais, culturais, de comportamento, surge durante a infância: o uso de instrumentos e a fala humana. Isso, por si só coloca a infância no centro da pré-história e do desenvolvimento cultural (1998, p.61).

Se pensarmos a cultura sob a perspectiva de Vygotsky, na qual o sujeito se desenvolve por meio da cultura que está inserido, podemos afirmar que a criança do século XXI imersa em uma sociedade dita "globalizada" e da chamada "era tecnológica" desde muito cedo irá se apropriar dos recursos tecnológicos cada vez mais precocemente. Isso porque esses artefatos tecnológicos estão cada vez mais inseridos em seu cotidiano e em suas relações sociais.

Se vivemos em uma sociedade que faz uso constante de recursos tecnológicos, forçamonos acreditar que a criança dessa sociedade irá sim se apropriar dessa "cultura digital/tecnológica", visto que é nessa cultura que a criança está inserida e que ao longo do tempo da sua história de vida social vem internalizando o que faz parte da cultura da sociedade que está inserida.

A aprendizagem não se dá de forma individualizada. Diante disso, Vygotsky propõe que há zonas de desenvolvimento, "a zona de desenvolvimento proximal define aquelas funções que ainda não amadureceram, mas que estão em processo de maturação, funções que amadurecerão" (VYGOTSKY, 1998, p. 97). Ou seja, a mediação é fundamental para a aprendizagem.

É importante lembrar que nem sempre a criança foi respeitada como é hoje. Houve uma época em que a figura da infância era considerada inferior, marcada como não importante e por isso as crianças eram excluídas da polis. Nesse período não havia um sentimento ou consciência de infância.

A infância e os elementos que atualmente fazem parte dela, a exemplo do brincar, constituem-se de forma diferenciada em cada momento histórico. Nesse sentido, as crianças vivenciam processos culturais vinculados aos seus familiares, muitos dos quais foram passados de geração em geração.

A infância é reinventada por cada sociedade. Cada sociedade pode criar a sua própria imagem do que são as crianças. Portanto, o brincar é um elemento importante pertencente à infância, que ao longo do tempo vem se modificando. É por meio da brincadeira que a criança se constitui sujeito, interage com o meio e com o outro; dessa forma, a criança se desenvolve e constrói sua identidade.

O modo de brincar vem ao longo dos anos se modificando. As crianças do "mundo moderno" ou da "era tecnológica" vivem cercadas dos mais diferenciados recursos tecnológicos. Estão em meio aos mais diversos aparelhos eletrônicos, como videogames, computadores, tablets, ipods, Mp3, Mp4, câmeras digitais, celulares e internet, construindo, desse modo, novos modos de brincar. A tecnologia vem ao logo do tempo influenciando o processo de socialização, de aquisição 
de novos valores, de percepção e ação sobre o mundo, o que inclui os modos de brincar, expressão privilegiada dessas relações (BITTENCOURT s.n.t).

O brincar não vem apenas se modificando no ato em si; vem se modificando também nos objetos do brincar - nos brinquedos. Há tempos atrás, as crianças brincavam nas ruas de várias brincadeiras, como o pega-pega, o esconde-esconde, a amarelinha. Hoje em dia as crianças da "era tecnológica" vem perdendo cada vez mais esses hábitos. É muito mais comum que elas fiquem cada vez mais dentro de casa brincando "sozinhas" com seus brinquedos eletrônicos.

Antigamente, os brinquedos eram mais artesanais e não eram muito sofisticados, por exemplo, o peão, a pipa, a bolinha de gude, a bola de futebol, a boneca de pano. Com o desenvolvimento da tecnologia os brinquedos estão cada vez mais robotizados. Segundo Silva (2012, p. 21):

A robótica com a criação de instrumentos robotizados já fazem parte do nosso cotidiano como nos eletrodomésticos, celulares, automóveis, internet e no universo infantil e já se estendeu ao campo dos brinquedos, através dos jogos virtuais como videogames, jogos interativos pela internet, (...) nas bonecas que falam nos minis laptop entre outros.

Desse modo, percebe-se que a criança que está inserida em uma sociedade globalizada e cercada de tecnologias passa então a internalizar essa cultura, assumindo assim novas formas de brincar. Silva (2012, p. 22) afirma que "não há como negar que os brinquedos evocam as formações do social. Estes objetos refletem os traços da cultura que se inscrevem.". O fato é que, ao longo do tempo e com o desenvolvimento de tecnologia, os modos de brincar vêm se modificando e cada vez mais as crianças fazem uso de recursos tecnológicos em seus momentos de brincadeira. Segundo Silva (2006),

As modernas tecnologias de informação e comunicação despertam a atenção e quase uma "fixação" por parte das crianças. Elas apresentam intensa motivação para o conhecimento e o manuseio dos computadores, jogos e agendas eletrônicas, e outros artefatos do gênero.

Cercadas dos mais variados recursos tecnológicos, as crianças utilizam cada vez mais o computador, afinal, ele está presente em diversos lugares que a criança frequenta, facilitando, assim, que esse sujeito entre em contato com esse recurso. Segundo Mota (2007, p. 13) "o computador, quando não está no ambiente principal da casa da criança, está no trabalho dos pais, na escola, na convivência com amigos e familiares, facilitando cada dia mais o acesso ao seu uso".

Como sujeito social e histórico pertencente a um determinado grupo social que internaliza a cultura a qual está inserida, pressupõe-se que a criança que vive em uma sociedade que faz uso diariamente de recursos tecnológicos e em particular do computador vai de alguma forma tentar interagir com esse equipamento - sendo este recurso que ao longo do tempo vem modificando a maneira de viver dos sujeitos, seja essa transformação para o bem ou para o mal, estes recursos já fazem parte do nosso dia a dia. Segundo Mota (2007, p. 31):

Após as últimas quatro décadas de informação e tecnologia, não é mais tempo de questionar se estas vieram para o bem o para o mal. Elas estão presentes em 
nossas vidas, transmitindo valores e padrões de condutas, socializando várias gerações e interligando o mundo todo, transformando as relações sociais.

Para nos mantermos inseridos no contexto social atual, na chamada sociedade tecnológica, é importante saber utilizar os recursos tecnológicos e, em particular, o computador. Pois, já há a percepção de que ele ganhou grande espaço em nossas vidas profissional, escolar/acadêmica e social.

Entende-se que lidar com estes recursos no contexto atual é necessário. Por estarem inseridas em uma sociedade tecnológica, as crianças já passaram a enxergar as tecnologias como um objeto comum à vida delas. De acordo com Mota (2007, p. 34), "A criança que convive em famílias que têm e fazem uso do computador, não vê a tecnologia como um objeto estranho a si, mas como um objeto social, um instrumento de mediação". Hoje em dia é muito comum observamos uma criança pequena "mexendo" (na visão adulta) no computador. A criança "mexe" nos botões (teclas), no mouse, tenta ligar/desligar. Decerto, é dessa maneira que a criança começa a estabelecer certa interação com a máquina. Segundo Silva Filho (1998 s.n.t):

As crianças interagem com os computadores através da pressão sobre as teclas, através da movimentação do joystick ou do mouse, ligando ou desligando o computador elas estão de certa maneira interagindo, estão interagindo de forma concreta quando observam o que acontece na tela, quando observam as reações que se dão em relação a sua iniciativa.

Porém, a interação não é demarcada apenas pelos atos mecânicos referentes aos toques da criança nos teclados ou tela. Essa é a parte mais aparente. A criança é um sujeito social que aprende através da interação com o meio em que vive e, por esta razão, a criança nascida na era tecnológica vai desenvolver vínculos com os recursos tecnológicos (computador e tablet) pelo simples fato de esses recursos estarem presentes no meio social ao qual pertence. Segundo Silva Filho (1998 s.n.t.):

As crianças adquirem conhecimento a respeito do mundo físico e social, no qual vivem a partir de jogos interativos que elas estabelecem com os objetos e as pessoas. Neste sentido, consideramos o computador como um meio que pode estimular as crianças a brincar e a realizar esses jogos.

Dessa maneira, entende-se que o computador por ser um objeto que está cada vez mais presente em nosso cotidiano, sendo utilizado pela criança como meio de lazer e entretenimento. Mota (2007, p. 13) afirma que "atualmente, é muito comum a criança, desde muito pequena, estar sentada com muita ou pouca frequência diante do computador como uma das formas lúdicas de entretenimento e lazer, fazendo deste, seu brinquedo eletrônico". Indubitavelmente, esse equipamento pode oferecer à criança momentos de diversão, por meio dos mais diferenciados jogos no próprio equipamento e na própria rede (jogos online e outros meios que proporcionam interação com outros sujeitos).

Percebe-se, pois, que o computador desperta na criança curiosidade e é essa curiosidade que faz com que a criança interaja e explore esse instrumento. Os jogos são recursos que fazem parte da vida do homem há muito tempo. Muitas vezes utilizados como um passatempo, do qual o sujeito acaba fugindo um pouco da sua realidade, o jogo é um recurso que proporciona ao 
homem manifestar a sua imaginação. É com o surgimento da modernidade que a criança passa a ter acesso aos jogos, já que antes os jogos só eram utilizados pelos adultos. Segundo Huizinga (2000 s.n.t.):

Encontramos o jogo na cultura, como um elemento dado existente antes da própria cultura, acompanhando-a e marcando-a desde as mais distantes origens até a fase de civilização em que agora nos encontramos. Em toda a parte encontramos presente o jogo, como uma qualidade de ação bem determinada e distinta da vida "comum".

O jogo é um elemento cultural que ao longo do tempo vem sendo ressignificado e fazendo mudanças na cultura do próprio homem; isso acontece desde os primórdios da humanidade. Os jogos, além de elemento cultural, é também um elemento que leva o sujeito a desenvolver sua criatividade e imaginação. Além disso, o jogo mexe com a parte motora, afetiva, cognitiva e social do sujeito que joga. Segundo Macedo; Pety; Passos (2000, p. 66) “[...] jogar viabiliza aprendizagens que podem ser aplicadas em diferentes situações (escolares ou não), como saber tomar decisões, antecipar, coordenar informações e comunicar ideias". Por meio do jogo a criança passa a dar significados diferentes aos objetos. De acordo com Carvalho e Oliveira (2014, p. 434):

é no jogo e por meio do jogo que a criança é capaz de atribuir significados diferentes aos objetos, desenvolver a sua capacidade de abstração e começar a agir independentemente daquilo que vê, operando com os significados diferentes da simples percepção dos objetos.

Ainda em conformidade com as autoras, o jogar pode fazer com que o sujeito "Jogador" adquirira estratégias para resolver problemas, permitindo que o jogador investigue e descubra qual a melhor maneira para jogar. O jogo é um recurso lúdico, ele permite que o sujeito desenvolva sua imaginação, sua capacidade de sistematizar e abstrair, sua capacidade de interagir socialmente, logo, permitindo que o sujeito desenvolva seu espírito construtivo.

Para Tezani (2006) o jogo não é só um passatempo, porque estimula o crescimento, o desenvolvimento, a coordenação muscular, as faculdades intelectuais, a iniciativa individual, favorecendo o advento e o progresso da palavra. Além disso, o jogo estimula o indivíduo a observar e conhecer as pessoas e as coisas do ambiente em que vive.

Durante a interação com o jogo a criança pode desenvolver hipóteses e pode também manifestar sua criatividade, descobrindo assim seu próprio eu. Jogar é mais que um passatempo, pois o jogo proporciona um momento de alegria, divertimento, entusiasmo, confiança, aprendizagens e desenvolvimento. Diante disso, afirma-se que "o uso dos jogos proporciona ambientes desafiadores, capazes de 'estimular o intelecto', proporcionando a conquista de estágios mais elevados de raciocínio." (REGO, 2000, p. 79). O jogo proporciona à criança um momento de aprendizagem mais atrativa e interessante, já que é através do brincar que a criança passa a articular teoria e prática e a formular hipóteses. Desde modo, sua aprendizagem se torna mais atrativa.

Por meio do jogo, a criança aprende a separar objeto e significado. De acordo com Tezani (2006), o jogo cria uma zona de desenvolvimento proximal na criança. É por meio da zona de desenvolvimento proximal que a criança vai situar o que ela já sabe fazer sozinha (zona de 
desenvolvimento real) e aquilo que ela ainda precisa aprender. Por outro lado, ela consegue fazer com a ajuda do outro mediando (zona de desenvolvimento potencial).

O jogo atua na zona de desenvolvimento proximal, realizando um intercâmbio entre a zona de desenvolvimento real, a qual abrange as aprendizagens já consolidadas, à zona de desenvolvimento potencial, que representa as aprendizagens que ainda vão se consolidar. (TEZANI, 2006, p. 10).

Ainda de acordo com a autora, o jogo representaria, então, a articulação entre o desejo, a afetividade, a inteligência e os processos de apropriação do conhecimento e o avançar das zonas de desenvolvimento (2006, p. 13). Durante o jogar a criança faz levantamento de suas hipóteses e busca desenvolver soluções. É por meio do jogar que a criança torna o que ela deseja em algo realizado. É por meio da sua imaginação que aquilo que era abstrato torna-se concreto, resultando, assim, em construção de conhecimento. Em suma, o jogo, além de elemento cultural, é também um elemento que leva o sujeito a desenvolver sua criatividade e imaginação. No jogo, o sujeito interage com outros sujeitos, ampliando a sua cultura. Nas palavras de Sarmento e Barra:

Em todos os casos, as crianças apresentam desempenhos caracterizados por níveis elevados de interactividade (não necessariamente à distância), de ludicidade, de capacidade reiterativa e de projecção imaginária para o "mundo do faz-de-conta". Estas características são bem expressivas da diferença dos mundos culturais das crianças e constituem, na acumulação e no grau do exercício, os principais traços distintivos das culturas infantis. [...]. (SARMENTO e BARRA, 2008, p. 19).

Assim, articula-se jogo e cultura. Brougère (1998) discute que, para uma atividade ser considerada jogo, deve-se respeitar alguns elementos: metacomunicação, regras, tomada de decisão por parte dos participantes, incerteza e a frivolidade e flexibilidade do jogo.

\section{RESULTADOS E DISCUSSÃO}

Para alcançarmos os resultados desta pesquisa, fizemos quatro dias de observação com a criança escolhida. No primeiro dia, cuja duração de observação durou $1 \mathrm{~h} 10 \mathrm{~min}$, observou-se que a criança não sabia ligar o computador; porém sua primeira ação ao entrar em contato com a máquina foi fazer uso do teclado.

No segundo dia de observação, que teve duração de $45 \mathrm{~min}$, a criança já se sentia mais à vontade e quando foi pedida para ligar o computador, ela imediatamente o ligou. Já no terceiro dia, que teve duração de $1 \mathrm{~h} 15 \mathrm{~min}$, pode-se perceber que houve um pequeno progresso da criança em relação à utilização da máquina; pois, ao entrar em contato com o equipamento a criança foi logo ligando o aparelho sem que fosse pedido pela pesquisadora.

O último momento de observação teve duração de $1 \mathrm{~h} 15 \mathrm{mim}$ e pode-se constatar que a criança já estava bem familiarizada com os fartefatos tecnológicos (computador e tablet). A criança já conseguia solucionar alguns problemas que apareciam na tela dos artefatos.

Em qualquer pesquisa que se faça, uma fase importante é a descrição e a coleta de dados. É por meio da coleta de dados que conseguiremos analisar e interpretar os dados colhidos para então definirmos o resultado da pesquisa. De acordo com Teixeira (2003, p. 178): 
abordar a análise de dados enquanto etapa do processo de investigação científica no campo das organizações configura-se como relevante, uma vez que a tentativa de identificar especificidades pode significar melhores condições para o desenvolvimento de novos estudos, com base num melhor e maior entendimento conceitual do processo, alinhado aos respectivos paradigmas.

Nos dois primeiros dias de observação que ocorreram nos dias 26 e 27 de agosto de 2013, a criança utilizou apenas o computador. Durante a utilização do computador, a criança fez uso do jogo Purble Place. Esse jogo é composto por três joguinhos: Comfy Cakes, Purble Pairse Purble Shop.

O Comfy Cakes tem como objetivo fazer com que o jogador faça os bolos de acordo com o bolo encomendado. A imagem de um bolo aparece em uma tela e o jogador deve fazer um bolo igual ao bolo que apareceu na tela. Esse jogo demanda do sujeito que o joga que ele se atente a uma sequência de fatos para cumprir o objetivo do jogo. Neste jogo, a criança pode trabalhar com formas e cores. Existem três tipos de fôrmas e cada uma delas representa uma forma - formato de coração, quadrado e círculo. Já as cores estão representadas no jogo como sendo a massa e a cobertura do bolo, isto é, a cor marrom representa a massa e a cobertura de chocolate, enquanto a cor rosa representa a massa e a cobertura de morango e, por fim, a cor amarela, que representa a massa e a cobertura de baunilha.

O Purble Pairs tem como objetivo fazer com que o jogador encontre os pares de cartas iguais numa espécie de jogo da memória. $O$ jogo é cronometrado e o jogador precisa ser rápido para encontrar os pares, pois se não encontrar durante o tempo ele perde o jogo. Esse jogo demanda do sujeito que o joga que ele encontre os pares iguais de forma rápida por conta do tempo. Além disso, esse jogo trabalha com a memorização do sujeito.

O Purble Shop tem como objetivo fazer com que o jogador encontre as características dos bonequinhos, dando-lhes olhos, nariz e boca. Diante do exposto, pode-se verificar que estes jogos são bastante coloridos e demandam dos jogadores atenção.

Já nos dias 29 e 30 de agosto de 2013 a criança fez uso do computador e do tablet. No computador, a criança continuou a fazer uso do jogo Purble Place, este já descrito anteriormente. Enquanto que no tablet criança fez uso de dois jogos, o Bubble Pop e Four. In. A.Line. O Bubble Pop tem como objetivo fazer com que o jogador remova as bolinhas da mesma cor que estão agrupadas. Este jogo demanda do jogador atenção na hora de remover as bolinhas. O Four. In. A.Line tem como objetivo fazer com que o jogador encaixe quatro bolinhas da mesma cor para ganhar o jogo. Neste jogo, o jogador disputa a jogada com a CPU; sendo que cada um joga uma vez até que consigam agrupar as quatro bolinhas.

Na primeira sessão, percebeu-se que a criança não sabia bem o que fazer quando colocada em frente ao computador. Ela estava meio receosa para interagir com o artefato tecnológico. A criança não sabia ligar o equipamento, entretanto, ao receber informação de como ligava o computador, logo em seguida fez uso dessa informação e ligou o aparelho. Nesse primeiro contato, pode-se perceber que a criança já tinha conhecimentos prévios sobre o uso do computador, pois a primeira reação dela foi apertar as teclas do teclado. Provavelmente ela já tinha visto alguém utilizando um computador e fazendo uso do teclado antes. Segundo Silva Filho (s.n.t.): 
As crianças interagem com os computadores através da pressão sobre as teclas, através da movimentação do joystick ou do mouse, ligando ou desligando o computador elas estão de certa maneira interagindo, estão interagindo de forma concreta quando observam o que acontece na tela, quando observam as reações que se dão em relação a sua iniciativa.

Aos poucos a pesquisadora inseria a criança naquele novo meio de interação, demonstrava o que ela poderia fazer no computador. Ao abrir a pasta de jogos, a criança demonstrou interesse pelo Purble place. Ao iniciar o jogo, a criança ainda não sabia bem o que fazer e algum tempo depois apareceu uma janela enquanto ela tentava jogar. Nesse momento ela não sabia o que fazer e olhou para a pesquisadora, que tenta auxiliá-la mostrando que em cima da tela havia um $\mathrm{X}$ e que ela poderia apertar nele para fechar a janela. A criança segue a instrução, o jogo reaparece e ela volta a jogar. Nesse momento percebe-se que mais uma vez a criança vai se apropriando de informações que auxiliam sua interação com o recurso tecnológico.

A criança inicia um novo jogo. Este jogo demandava dela que fosse clicando em setas para que o bolo chegasse à última etapa do jogo. Entretanto, a criança não sabia como o jogo funcionava, tivemos de auxiliá-la, dando informações para que ela conseguisse jogar. Depois das informações passadas, ela começa a compreender a finalidade do jogo. Desse modo, começou a usar as setas que eram importantes para a conclusão do jogo, ou seja, ela passou a se apropriar dessas informações e por meio delas começou a interagir com o jogo.

Na primeira sessão, a criança mostrou um pouco de dificuldades em relação ao uso do computador, do mouse e do jogo. A criança sabia que o computador servia para mexer e que tinhas jogos, provavelmente por já ter visto alguém fazendo uso do computador dessa maneira.

Na primeira observação a criança não sabia bem o que fazer quando colocada em frente ao computador; mas, no segundo dia já se mostrava mais à vontade com este recurso tecnológico. Percebeu-se que houve uma apropriação tecnológica pela criança, pois no primeiro dia ela não sabia como ligar o computador e apenas com o auxílio da pesquisadora a criança pôde ver onde o equipamento era ligado. Na segunda observação, ela já sabia como ligar o equipamento, quando foi dito que poderia ligar o aparelho, ela o ligou imediatamente. Isso remete à ZDP proposta por Vygotsky, que é quando a criança aprende com a interação com outros, nesse caso a pesquisadora. Essa interação ativa os conhecimentos que estão potencialmente no sujeito.

Logo, a criança pediu para jogar; entretanto, ela não sabia como chegar até o jogo. Ao começar a jogar, percebeu-se também que a criança conseguiu se apropriar dos objetivos dos jogos. Na primeira observação ela ficou um pouco sem saber o que fazer. Contudo, no segundo dia de observação, já conseguia solucionar os problemas que apareciam durante o jogo. Por exemplo, ela estava jogando um joguinho da memória que demandava dela que encontrasse as figuras iguais, formando os pares. $\mathrm{O}$ jogo contava com um relógio e o tempo acabou. Ela não conseguiu encontrar todas as peças, então o jogo finalizou e logo em seguida apareceu uma janela informando que ela perdeu o jogo e embaixo apareciam três perguntas: jogar novamente, menu principal e sair. A criança solucionou o problema clicando no X que aparecia na janela; logo voltou a jogar.

Nesse ínterim, ela também utilizou um conhecimento prévio e deslocou o comportamento de clicar no $X$ para fechar o outro aplicativo para fechar o jogo que estava utilizando. Isso demonstra que o jogo estava de acordo com o desenvolvimento cognitivo da participante da 
pesquisa, pois a mesma demonstrou conhecimentos para navegar adequadamente em sua interface.

Por conseguinte, percebe-se que houve uma apropriação tecnológica pela criança. Na sessão anterior, tinha acontecido algo parecido: enquanto ela jogava aparece uma janela com vários vídeos; informamos que poderia apertar no X que aparecia na tela para fechar, e ela apertou, voltando assim a jogar. Portanto, percebe-se que ela se apropriou dessas informações e quando foi necessário fez uso delas novamente. Nessa segunda observação, a criança foi utilizar um novo jogo e esse, inicialmente, pedia para que o jogador colocasse o seu nome. Nesse momento a criança teve um pouco de dificuldade em encontrar as letras do seu nome no teclado. Entretanto, ela conseguiu digitar sem problemas.

Já na terceira observação, pode-se perceber que a criança estava bastante familiarizada com o recurso tecnológico, pois a criança ligou o computador sem que a pesquisadora precisasse falar que ele poderia ser ligado naquele momento. Depois de ligado, a criança buscou pelo jogo que vinha explorando nas sessões anteriores. A criança, no entanto, ainda tinha dificuldades em conseguir chegar ao jogo que queria; contudo, percebeu-se que a criança já tinha conseguido apropriar-se da funcionalidade do jogo e, ainda, conseguia solucionar os problemas que apareciam na tela quando o jogo terminava.

Foi entregue para a criança, nessa sessão, um tablet. Não se pode deixar de notar que ela já tinha um conhecimento antecipado a respeito desse aparelho, pois ao ser questionada se conhecia aquele tipo de aparelho, imediatamente respondeu que era um tablet, o que significa que ela já tinha visto um tablet antes. Ao ser perguntada sobre a utilidade daquele objeto, ela responde que servia para tirar e visualizar fotos, o que nos leva a crer que a criança provavelmente viu alguém tirando e vendo fotos neste tipo de aparelho. Podemos destacar também que a criança já tinha uma apropriação tecnológica sobre o uso do tablet, uma vez que ao entrar em contato com o aparelho deslizou os seus dedos sobre a sua tela, não apresentando reações diferentes, como a de tentar utilizar o aparelho como se tivesse lendo um livro ou fazendo uso do movimento de passar as páginas. Isso nos leva a acreditar que a criança já tinha visto alguém utilizando esse tipo de instrumento anteriormente, ficando claro para ela que o uso do tablet se dá por meio de toques com o dedo na tela.

Passamos algumas informações sobre o que a criança poderia encontrar no tablet, por exemplo, usar a internet e jogar. Ela se interessou por dois jogos, o primeiro deles demandava que fosse removendo bolinhas de cores semelhantes que se encontravam agrupadas. Percebeu-se que a criança conseguiu entender a funcionalidade do jogo; entretanto, quando o jogo terminou, apareceu uma janela informando a pontuação e um botão para começar um novo jogo. Neste momento ela não sabia bem o que fazer; fora dada uma dica e logo ela conseguiu resolver o problema e voltou a jogar.

Depois desse jogo a criança pediu para acessar outro. Nesse momento ela recebeu algumas instruções, a fim de que encontrasse o jogo que queria sozinha. Durante o novo jogo, apareceram várias janelas, porém ela mesma resolveu o problema clicando em uma seta - ao apertar o jogo reaparece e a criança volta a jogar.

Podemos notar que a criança foi ao longo das sessões se apropriando de informações passadas pela pesquisadora; conseguindo, assim, interagir com o artefato tecnológico. A criança 
teve um pouco de dificuldades em conseguir encontrar os jogos que queria, mas fica um tempo mexendo, tocando nos ícones que aparecem na tela. Pode-se notar que a criança logo se apropria das informações passadas pela pesquisadora e durante a observação vai conseguindo resolver os problemas que foram surgindo, por exemplo, usar a seta que estava embaixo da tela para sair de determinados ambientes.

Durante os três dias de observação, percebeu-se que a criança tinha um pouco de dificuldades de encontrar no computador o jogo que ela gostou de jogar. Este se encontrava em uma pasta de jogos e para chegar ao jogo a criança deveria ir até o botão iniciar e depois clicar em jogos. Durante os três dias de observação a criança teve essa dificuldade; entretanto, na quarta e última observação, nota-se que a criança apropriou-se dessa informação, isto é, já conseguia fazer o caminho até a pasta jogos.

Ao iniciar a quarta observação, fora sugerido para a criança entrar na internet. Ela clicou no ícone do navegador da internet (Google Chrome); no entanto, ela não conseguiu abrir o navegador. A criança, na verdade, queria mesmo jogar, então, perguntei para a criança: "Onde a gente encontra o jogo?" ela respondeu: "-aperta e depois aperta no azul", ou seja, ela sabia que tinha que apertar no botão iniciar para conseguir chegar ao jogo. Pediu-se para a criança apertar no botão que ela achava que deveria clicar logo a janela do botão iniciar aparece. A criança fica um pouco pensativa, mas clica no botão em que aparece a palavra jogos e aguarda que essa pasta abra. Ao iniciar a pasta de jogos a criança teve um pouco de dificuldades em encontrar o jogo que queria; pois, na tela apareciam vários jogos e para que ela encontrasse o jogo que queria deveria utilizar uma barra de rolagem; no entanto, a criança teve dificuldade em resolver esse problema.

Mais uma vez, fora-lhe dada uma pequena ajuda. Mostrou-se a seta (a barra de rolagem) onde ela poderia subir e descer com o mouse, podendo assim visualizar todos os jogos que estavam na lista. A criança logo se apropria dessa informação e resolve o problema, chegando então ao jogo que queria. Depois de algum tempo jogando no computador a criança pega o tablet e sente um pouco de dificuldade em ligá-lo. Diante disso, dirigimos a ela a seguinte pergunta: "como faz para ligar?" ela responde: "aperta no botão do meio"; mesmo assim não consegue ligar o aparelho. Algum tempo depois a criança consegue ligar o aparelho. Perguntada sobre o que queria fazer responde: "jogar". Logo em seguida outra pergunta foi feita: “como encontra o jogo?". Nota-se que a criança fica explorando o aparelho, tentando encontrar o jogo, e no meio desse recurso de exploração percebe-se que se utiliza de algumas apropriações tecnológicas, como usar a seta de voltar para sair de um ambiente indesejado.

Depois de algum tempo jogando o Bubble Pop no tablet, a criança decide ir para outro jogo; entretanto, a criança ainda tinha dificuldades de encontrar as coisas que ela queria. Quando finalizou o jogo que jogava, apareceu na tela uma janela informando a pontuação e um botão com "new game"; mas a criança queria ir para outro jogo. Então, perguntei para a criança: "o que você precisa fazer para ir para o outro jogo?" ela respondeu: "aperta na casinha". Ela clica no botão "casinha" e volta para a tela principal do aparelho. Feito isso, explora o aparelho e em meio a esse percurso consegue chegar a uma janela que contém todos os ícones disponíveis no aparelho. Logo encontra o jogo que tanto queria. Quando o jogo inicia, percebe-se que a posição do aparelho em relação ao jogo se encontrava de cabeça para baixo. Tempos depois, a criança percebe e imediatamente muda a posição do aparelho, demonstrando conhecimento sobre a mudança da apresentação da tela que ocorre com o tablet, diferentemente de outros artefatos tecnológicos. 
Perante o descrito, pode-se inferir que a criança está no nível da apropriação tecnológica, tal como descrito por Oliveira (2006), no sentido de que se ativou a curiosidade e o interesse pelo computador numa perspectiva lúdica. O nível descritivo, enumerativo, narrativo é caracterizado pela curiosidade e exploração do computador, com perguntas recorrentes sobre o funcionamento da máquina, experimentação de possibilidades mediadas pelo lúdico. Apesar de a criança não explorar de forma a fazer muitas perguntas, infere-se que a mesma encontra-se nessa fase, sendo que a forma de interação verbal pode ser relacionada com características de personalidade e de pouco conhecimento da entrevistadora.

Diante do exposto, podemos compreender que a criança, mesmo não tendo contato diário e nem fazendo uso dos recursos tecnológicos (computador/tablet) em seu dia a dia, já possuía alguns conhecimentos prévios e algumas concepções formadas sobre estes aparelhos. Afinal, essa criança, em algum momento de sua vida, pôde observar alguém próximo a ela fazendo uso desses artefatos digitais anteriormente; além disso, a criança já tinha como apropriação tecnológica o uso do celular, pois, em meio a muitos equipamentos eletrônicos, o aparelho de celular era o recurso tecnológico mais presente em sua rotina e que para ela era também um objeto de entretenimento/lazer, tendo em visto que fazia uso de jogos no celular de sua mãe.

Não se pode minimizar a importância da mídia na construção do comportamento da criança, na medida em que os artefatos tecnológicos são exibidos tanto com fins de comércio, quanto de uso cotidiano. Pode-se notar que a criança durante os quatro dias de observação foi se apropriando cada vez mais de informações sobre estes recursos, informações estas que contribuíram para a sua interação com estes equipamentos.

Pode-se perceber que a criança já tinha uma concepção formada sobre os equipamentos tecnológicos (computador e tablet), pois ao ser questionada sobre a serventia destes aparelhos, a criança deixou claro que o computador servia para "mexer e jogar" e o tablet servia para "tirar foto e ver foto". Ao ser questionada sobre o tablet a criança disse que ele parecia com uma televisão. Perguntei para a criança se o tablet era um computador e ela respondeu que "Não". Apesar de não saber esclarecer e fazer o processo de metacognição, a criança soube a partir de sua experiência cotidiana com os artefatos diferenciá-los. Na prática cotidiana, o tablet é muito visto como máquina fotográfica e, na prática da criança, esse deve ser o uso mais repetitivo. Sendo assim, a relação feita entre televisão e tablet, no sentido de que ambos têm a tela como interface mais visível. Acredita-se que, se a criança for exposta a situações de maior experimentação com o tablet, tal concepção poderá ser alterada.

Para a criança a televisão serve para assistir e o livro serve para estudar e fazer tarefa, demonstrando uma separação entre artefatos para diversão e para estudo. O livro ainda é colocado como objeto de estudo vinculado à escola. A televisão é tida a partir da perspectiva lúdica. A divisão dos artefatos tecnológicos na cultura deve-se também ao uso que se faz dele nas atividades de casa, da escola e na mídia. Podemos, aqui, refletir sobre os usos que a escola dá para os diversos artefatos e sobre a divisão que ela mesma margeia ao não utilizar a televisão também como artefato para estudo, por exemplo.

Depois de quatro dias de observação, percebe-se que os recursos tecnológicos computador e tablet foram para a criança objetos que serviram como entretenimento; pois, a única coisa que a 
criança teve interesse em explorar foram os jogos. Mostrando assim, que sua atividade principal estava relacionada à ludicidade.

\section{CONCLUSÃO}

Os artefatos tecnológicos estão muito presentes em nosso dia a dia e a cada vez mais invadem a rotina das crianças. Por esta razão, esta pesquisa teve como objetivo principal analisar como se dava a interação de uma criança em processo de alfabetização, com seis anos de idade e que nunca antes teve contato com os recursos tecnológicos computador e tablet.

Para atingir nosso objetivo, durante quatro dias, fizeram-se observações da interação da criança com esses recursos. Além das observações, foram feitas algumas perguntas para a criança sobre estes artefatos, com o objetivo de compreender qual era as suas concepções acerca destas tecnologias.

Diante da avaliação dos dados coletados por meio das observações e das entrevistas para alcançar a resposta sobre o problema proposto nesta pesquisa: "como uma criança não alfabetizada que nunca teve contato com os artefatos tecnológicos computador e tablet interage com estes recursos e quais são as suas concepções acerca destes recursos?" chegou-se a seguinte conclusão: que mesmo sem fazer uso dos artefatos tecnológicos computador e tablet a criança já tinha conhecimentos prévios sobre a usabilidade destes recursos.

Isso pode ser percebido no primeiro dia de uso do computador, uma vez que sua reação inicial foi a de fazer uso do teclado, o que significa que ela já tinha certa apropriação tecnológica do computador, por ter visto alguém fazendo uso desse aparelho em algum momento. Outro indício de que a criança já possuía certa concepção formada sobre esses recursos tecnológicos aparece quando é questionada sobre o uso desses artefatos. Ela diz que o computador serve para "mexer e jogar"; enquanto que o tablet serve para "tirar e ver fotos". Isso só reafirma o nosso entendimento de que em algum momento da sua vida, a criança pode ter visto alguém utilizando algum desses recursos.

A criança também tinha suas concepções formadas sobre a televisão e o livro. Ela deixou claro que a televisão servia para assistir e o livro para estudar e fazer tarefa. Para ela, o tablet não era um computador. Ao ser questionada sobre o porquê do tablet não ser um computador ela não soube responder. Ademais, para ela esses recursos serviam apenas como entretenimento, pois durante os quatro dias de observação, ela só se interessou pelos jogos. Foram eles, portanto, os únicos recursos que a criança teve o interesse de interagir. É importante ressaltar que a criança já tinha tido contato com alguns jogos digitais antes, em um determinado momento ela diz que já fez uso de jogos no celular de sua mãe.

Diante dessas informações e embasados na perspectiva de Vygotsky sobre cultura percebese que a criança já se apropriou e internalizou alguns conhecimentos sobre a "cultura digital"; afinal, essa criança se encontra em um meio social no qual o uso de artefatos tecnológicos são cada vez maiores.

Espera-se que esse estudo possa contribuir para a discussão da importância dos recursos tecnológicos, em especial o computador e o tablet na rotina da criança e por isso buscou-se compreender sua interação com esses equipamentos. Pretende-se, pois, com esta pesquisa, indicar 
novos caminhos no processo de reflexão de certas especificidades a respeito da problemática interação - criança - computador e tablet, a partir de observações de uma criança. E, que o referido estudo suscite em contribuições sobre a importância dos recursos tecnológicos na vida escolar e social da criança.

\section{REFERÊNCIAS}

1. BARBOSA, M. C. S. Jogo, brinquedo, brincadeira e a educação. Educação \& Sociedade, ano XVIII, n.59, agosto 1997. Disponível em: http://www.scielo.br/pdf/es/v18n59/18n59a10.pdf Acesso em:28/08/2013

2. BITTENCOURT, M.I.G.F. Brincando na era da tecnologia. LABORE Laboratório de Estudos Contemporâneos. POLÊM!CA Revista Eletrônica. UERJ. Disponível em: http://www.polemica.uerj.br/pol22/oficinas/artigos/lipis_2.pdf Acesso em:02/10/2013

3. BRASIL, Ministério da Educação e do Desporto, Secretaria de Educação Fundamental. Referencial curricular nacional para a educação infantil. Brasília: MEC/SEF, 1998.

4. Disponível em: http://portal.mec.gov.br/seb/arquivos/pdf/rcnei_vol1.pdf Acesso em: 19/09/2013.

5. BROUGERE, Gilles. A criança e a cultura lúdica. Rev. Fac. Educ., São Paulo, v. 24, n. 2, p. 103116, July 1998. Available from <http://www.scielo.br/scielo.php?script=sci_arttext\&pid=S 0102-25551998000200007\&lng=en\&nrm=iso>. access on 10 Nov. 2015. http://dx.doi.org/10.1590/S0102-25551998000200007.

6. CARVALHO, L. R. R. C.; OLIVEIRA, F. N. Quando o jogo na escola é bem mais que jogo: possibilidades de intervenção pedagógica no jogo de regras Set Game. Rev. bras. Estud. pedagog. (online), Brasília, v. 95, n.240, p. 431-455, maio/ago. 2014. Disponível em: http://rbep.inep.gov.br/index.php/RBEP/article/viewFile/3104/2048 Acesso em: 12/12/2013

7. CASTRO, S.M.J. Softwares para a educação infantil: Um olhar pedagógico. Universidade Federal de Santa Catarina, 1998. Disponível em:

8. http://www.portalanpedsul.com.br/admin/uploads/1998/Educacao_infantil/Trabalho/04_45 _34_SOFTWARES_PARA_A_EDUCACAO.pdf Acesso em: 16/09/2013

9. DIEHL, Astor Antônio; TATIM, Denise Carvalho. Pesquisa em ciências sociais aplicadas: métodos e técnicas. São Paulo: Pearson Prentice Hall, 2004.

10. FALKEMBACH, G. A. M. Concepção e desenvolvimento de material educativo digital. Universidade Federal do Rio Grande do Sul. Centro Interdisciplinar de Novas Tecnologias na Educação. s.n.t. Disponível em: http://penta3.ufrgs.br/midiasedu/modulo13/etapa3/leituras /arquivo/Artigo1_3.pdf Acesso em: 20/08/13

11. GIL, Antônio Carlos. Métodos e técnicas de pesquisa social. São Paulo: Atlas, 2009.

12. HOFF, M. S.; WECHSLER, S. M.. A prática de jogos computadorizados em um grupo de adolescentes. Rev. Estudos de Psicologia, PUC-Campinas, v. 19, n. 2, p. 59-77, maio/agosto 2002. Disponível em: http://www.scielo.br/pdf/estpsi/v19n2/a04.pdf Acesso em: 05/09/2013

13. HUIZIGA, Johan. Homo Ludens. Coleção Estudos. 4ạ ed. - reimpressão. São Paulo: Perspectiva, 2000. Disponível em: http://jnsilva.ludicum.org/Huizinga_HomoLudens.pdf Acesso em: 
$20 / 08 / 2013$

14. JUCÁ, S. C. S. A importância dos softwares educativos na educação profissional. In: SEMINFO, 2006, Torres - RS, p. 88-94. Disponível em: http://www.seminfo.com.br/anais/2006/pdf/a12 .pdf Acesso em: 06/08/2013

15. KENSKI, V. M.. Educação e Tecnologias: O Novo Ritmo da Informação. Campinas: Papirus, 2007.

16. KOVATLI, Marilei de Fátima; TORRES, E.F.; ALVES, J.B.M.. Estratégias para estabelecer interação de crianças com autismo e o computador. Rede SACl. 14/12/2004. Disponível em: http://saci.org.br/?modulo=akemi\&parametro=14092 Acesso em: 21/08/2013

17. MACEDO, L. de; PETTY, A. L. S.; PASSOS, N. C. Aprender com jogos e situações problemas. Porto Alegre: Artes Médicas, 2000.

18. MOITA, Filomena. Culturas juvenis e jogos eletrônicos: que currículo é esse?. In: Revista Interact. s.n.t. Disponível em: http://www.filomenamoita.pro.br/pdf/curriculo.pdf Acesso em: 05/08/2013

19. . Juventude e jogos eletrônicos: Que currículo é esse? Universidade Federal da Paraíba. s.n.t. Disponível em: http://www.bocc.ubi.pt/pag/moita-filomena-jogos-electronicos .pdf Acesso em: 05/08/2013

20. MOTA, A. B. Criança e Mídia - o acesso ao computador e seus reflexos nos saberes da criança de educação infantil. Curitiba, 2007, 135f. Dissertação (Mestrado em Educação: Cultura, Escola e Ensino) - Universidade Federal do Paraná. Disponível em: http://www.ppge.ufpr.br /teses/M07_mota.pdfAcesso em: 20/09/2013

21. NICOLACI-DA-COSTA, A. M. Impactos Psicológicos do Uso de Celulares: uma Pesquisa Exploratória com Jovens Brasileiros. Psicologia: Teoria e Pesquisa, UNB, v. 20, n.2, p. 165-174, 2004. Disponível em: http://www.scielo.br/pdf/ptp/v20n2/a09v20n2.pdf Acesso em: $10 / 09 / 2013$

22. _. Primeiros contornos de uma nova "configuração psíquica". Cad. CEDES, Unicamp Campinas, v. 25, n.65, p. 71-85, jan./abr. 2005. Disponível em: http://www.scielo.br/pdf/ ccedes/v25n65/a06v2565.pdf Acesso em: 10/09/2013

23. OLIVEIRA, E. S. G. Criança e computador: interação que impulsiona o desenvolvimento e a aprendizagem. rev.Colabor@, v.3, n.11, julho 2006.Disponível em: http://www.ricesu.com. br/colabora/n11/artigos/n_11/pdf/id_02.pdf Acesso em: 14/09/2013

24. REGO, T. C. Vygotsky: uma perspectiva histórico-cultural da educação. 10ạ ed. Petrópolis: Vozes, 2000.

25. SARMENTO, M. J.; BARRA, S. M. Os saberes das crianças e as interações na rede. Zero-a-Seis, Florianópolis, v. 8, n. 14, p.1-20. 2008.

26. SHIMABUKURO, Renata Yumi; UEDA, Cauê. Avaliação do site "Cocoricó" com crianças em idade pré-escolar. s.n.t. Disponível em: http://www.mundodesofia.com.br/downloads/arti go_sitecocorico.pdf Acesso em: 23/07/2013

27. SILVA, A. T. T.A infância e o brincar na era tecnológica: a escola em questão. XVI ENDIPE Encontro Nacional de Didática e Práticas de Ensino - UNICAMP - Campinas - 2012. Disponível em: http://www2.unimep.br/endipe/2028c.pdf Acesso em: 12/09/2013 
28. SILVA FILHO, J. J. Criança - Computador: Um exame das possibilidades pedagógicas. In: IX ENCONTRO NACIONAL DE DIDÁTICA E PRÁTICA DE ENSINO, 1998. ANAIS. Águas de Lindóia/SP. v.1. p.111-111. Disponível em: http://www.portalanpedsul.com.br/admin/up loads/1998/Educacao_infantil/Trabalho/04_40_25_CRIANCA_COMPUTADOR.pdf Acesso em: 04/09/2013

29. TAROUCO, L. M. R.;ROLAND, L. C. et al. Jogos educacionais. CINTED-UFRGS. v.2. n.1, março, 2004. Disponível em: http://seer.ufrgs.br/renote/article/view/13719/8049. Acesso em: $19 / 09 / 2013$

30. TEIXEIRA, E. B. A Análise de Dados na Pesquisa Científica: importância e desafios em estudos organizacionais. Desenvolvimento em Questão, ljuí-RS, v.1, n.2, p. 177-201, 2003. Disponível em: file://C:/Users/HP/Downloads/Teixeira_2003_A-analise-de-dados-na-pesqui sa_20204.pdf Acesso em: 02/09/2013

31. TEZANI, Thaís Cristina Rodrigues. O jogo e os processos de aprendizagem e

32. Desenvolvimento: aspectos cognitivos e afetivos. Educação em Revista, Marília, v.7, n.1/2, p. 1-16, 2006. Disponível em: http://www.profala.com/artpsico38.htm Acesso em: 26/07/2013

33. VALENTE, J. A. Questão do software: parâmetros para o desenvolvimento de software educativo. Núcleo de Informática Aplicada à Educação. Universidade Estadual de Campinas. NIED - Memo. n.24, 1989. Disponível em: http://www.nied.unicamp.br/ojs/index.php/me mos/article/view/79/78Acesso em: 26/07/2013

34. YIN, R. Estudo de caso. Planejamento e Métodos. Porto Alegre: Bookman, 2005. 